\title{
Scientific publishing - an unfair playing field
}

\author{
Jonathan Pimm ${ }^{1}$
}

The Psychiatrist (2013), 37, 281-282, doi: 10.1192/pb.bp.113.044768

${ }^{1}$ Editor, The Psychiatrist

Correspondence to Jonathan Pimm (tp@rcpsych.ac.uk)

\begin{abstract}
Summary Standards and the pursuit of excellence are vital in healthcare and scientific investigation. Researchers must seek the most efficient, rigorous and robust methods available. Scientific journals acting as information distributors should only publish quality studies; such an ideal has become increasingly difficult to attain. To compete in the imperfect market of scientific publishing, The Psychiatrist will be open access from January 2014 and articles will be freely available ahead of print. There will be no publication costs to authors for at least the first 12 months and the journal will be re-launched under its old familiar name - the Psychiatric Bulletin.
\end{abstract}

Declaration of interest None.
The pursuit of excellence and the necessity to ensure standards are crucial in healthcare and in science generally. Therefore, researchers must strive to undertake their work with the most rigorous and robust methodologies available. And because scientific journals are the main conduit for disseminating research findings, they also have a duty to only publish studies reaching a certain level of quality. Numerous organisations including the International Committee of Medical Journal Editors, ${ }^{1}$ the Council of Science Editors ${ }^{2}$ and the European Association of Science Editors $^{3}$ have set out requirements and/or guidelines detailing how to achieve satisfactory standards.

In recent years, the number of scientific journals has grown exponentially. However, a relatively small handful of publications still carry the majority of important and ground-breaking articles; this collection of journals includes the likes of Nature, Science, The New England Journal of Medicine and The Lancet. In addition to this elite group are a number of less well-known but still highly rated and professional journals responsible for publishing excellent work.

Further down the pecking order are journals including The Psychiatrist and many other small journals - that have so far failed to break through into the higher echelons of relevance and scientific respect. Often, these journals are stuck in a vicious circle of inadequacy; without sufficient kudos, they cannot attract the high-quality articles needed to gain recognition. Top-tier scientists rarely submit work to the lower-level journals for obvious reasons: these journals do not bring the desired publicity and what comes with it - jobs and funding streams. Similarly, less productive authors shun lower-ranked journals in an effort to improve their own status, and hence the vicious circle. ${ }^{4}$

Low-level journals may therefore struggle to even fill a whole edition with quality manuscripts, thereby leading to a trade-off between standards and quantity. For the editor, whose role is gatekeeper, this may mean retrieving papers from the spike or the trash in order to avoid a largely blank edition! This may result in a poor-quality product reflected in weak study design, limited statistical analysis and bad writing, which is compounded by a peer review process that relies on inexperienced and often uninterested reviewers. ${ }^{5}$

There are certain exceptions to these criticisms. In a best-case scenario, smaller journals can provide a useful platform for good-quality research, for example to report studies aimed at specialised academic disciplines or those that appeal to a limited geographic area. What the journals should not be are repositories for untrustworthy research that has been rejected everywhere else. Bad research benefits nobody - and indeed may cause harm if used in policy decisions - except perhaps researchers trying to pad their CVs. Unfortunately, bad research may actually be the norm.

In a perfect market, economists would be content to let competition run its course. But the world of academic publishing is certainly not a perfect market; among other things, peer review and editorships are generally volunteer positions and there is little recourse for low standards.

Of course, the best way forward is to try to improve the standard of the lower-ranking journals. This, however, is not an easy task; reversing years of entrenched mediocrity takes a great deal of effort. Here at The Psychiatrist, the belief is that the need for betterment is vital; such a potentially valuable resource cannot be allowed to die - at least not without a struggle. Over the past 12 months, efforts have been made to improve things; the standard for article acceptance has been gradually increased and the review process has become more streamlined thanks for the most part to the recruitment of a board of motivated, younger professionals from diverse backgrounds. The more observant readers will also have noticed additional evidence of change - the number of articles per edition has been reduced.

Further, to reach a wider audience and to increase appeal to potential contributors deciding where to 
publish, The Psychiatrist will be open access from 2014, with no cost to authors for at least the first 12 months. Further still, publishing ahead of print will be introduced and the frequency of editions will be reduced from monthly to bimonthly, with the first edition due in February 2014. And finally, to coincide with these changes and to give a clear signal that the journal welcomes articles from health professionals, carers, lawyers, all members of the multidisciplinary team, and all stakeholders involved in the treatment of people with mental illness including, of course, service users themselves, the journal is to be re-launched under its old familiar name - the Psychiatric Bulletin.

Other strategies for improvement will include the production of themed editions focusing on hot topics such as culturally informed psychiatry, sustainable public and mental health, and the examination of important legal issues such as the use of community treatment orders.

It is hoped that these changes will enhance the reading experience of The Psychiatrist's audience and also secure the production of a higher-quality product for the future.

\section{Acknowledgement}

Special thanks to Noah Scovronick for feedback on the article content.

\section{About the author}

Jonathan Pimm is Editor of The Psychiatrist, a consultant psychiatrist at East London NHS Foundation Trust, and an honorary senior clinical lecturer at Barts and the London School of Medicine and Dentistry, UK.

\section{References}

1 International Committee of Medical Journal Editors. Uniform Requirements for Manuscripts Submitted to Biomedical Journals. ICMJE, 2010 (http://www.icmje.org/urm_main.html). Accessed July 2013.

2 Council of Science Editors. CSE's White Paper on Promoting Integrity in Scientific Journal Publications, 2012 Update. CSE, 2012 (http:// www.councilscienceeditors.org/i4a/pages/index.cfm?pageid=3331). Accessed July 2013

3 European Association of Science Editors. EASE Guidelines for Authors and Translators of Scientific Articles to be Published in English. EASE, 2013 (http://www.ease.org.uk/publications/author-guidelines). Accessed July 2013.

4 Maruišić A, Maruišíć M. Small scientific journals from small countries: breaking from a vicious circle of inadequacy. Croat Med J 1999; 40: 508-14.

5 Maruišíć M, Maruišíć A. Good editorial practice: editors as educators Croat Med J 2001; 42: 113-20. 